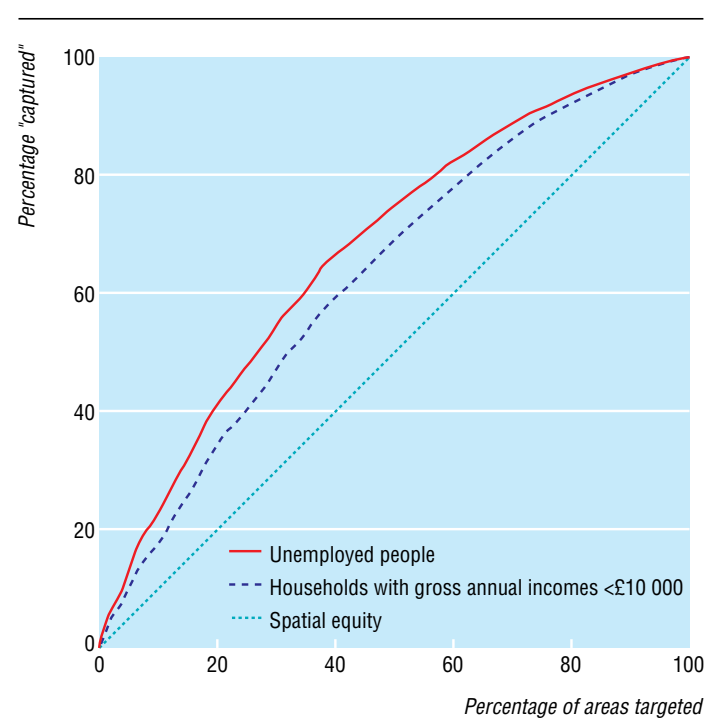

Cumulative proportion of unemployed individuals and households with gross annual incomes $<£ 10000$ in Scotland that would be captured for each postcode sector if Carstairs scores were used as a basis for targeting

a percentage of all low income households $(\mathrm{n}=704$ 066). Cumulative proportions for the total number of sectors and the total population contained within those sectors were also calculated.

On the basis of these results, if $20 \%$ of the most deprived sectors in Scotland (1 205 833/4 998202 (24\%) of the population) were targeted, $41 \%$ of unemployed people and 34\% of low income households would be "captured" (figure). By targeting 254 postcode sectors (1 501569 (30\%) of the population), resources could be directed to $48 \%$ of unemployed people and $40 \%$ of low income households. If $55 \%$ of the postcode sectors are targeted $(62 \%$ of the population), $80 \%$ of unemployed people and $74 \%$ of low income households are captured, but even then, 20\% and $26 \%$, respectively, are excluded. Modest improvements in capture rates $(2-6 \%)$ were achieved when the analysis was repeated using census enumeration districts (data not shown).

\section{Comment}

This analysis reaffirms Townsend's argument that the selective targeting of resources on an area basis would miss more deprived people than it would include. On the basis of Carstairs scores, more than $60 \%$ of the population in Scotland would need to be targeted to include $74 \%$ of low income households. The poor sensitivity of an area based approach means that the group of people to whom resources are directed includes people who are not poor. There are higher concentrations of poverty in some areas; however, the current increase in area based initiatives ignores the wide spatial distribution of deprived people. Only a small proportion of government spending is directed towards area initiatives, but their high profile implies that deprivation is a problem only within certain areas. However, deprived areas can include people who are not deprived and vice versa. Debate continues about whether the health experience of poor people in deprived areas is worse than that encountered by other poor people. ${ }^{5}$ Targeting deprived areas may have merits, but a greater emphasis on national strategies is the key to dealing with poverty and improving the health of the population.

I thank David Morrison and Anne Ellaway who commented on an earlier draft of the paper.

Contributors: PM initiated the study, formulated the research question, analysed and interpreted the results, wrote the paper, and is guarantor.

Funding: MRC Social and Public Health Sciences Unit is funded by MRC and Chief Scientist Office of Scottish Executive Health Department.

Competing interests: None declared.

1 Carstairs V, Morris R. Deprivation and health in Scotland. Aberdeen: Aberdeen University Press, 1992.

2 Townsend P. Poverty in the United Kingdom: a survey of household resources and standards of living. Harmondsworth: Penguin, 1979.

3 Holtermann S. Areas of urban deprivation in Great Britain: an analysis of the 1971 census data. In: Social Trends 6. London: Office for National Statistics, 1975:33-47.

4 CACI Information Services. PayCheck report. CACI's income model. London: CACI, 1997.

5 Sloggett A, Joshi $\mathrm{H}$. Higher mortality in deprived areas: community or personal disadvantage? BMJ 1994;309:1470-4.

(Accepted 30 April 2001)
Atherosclerosis and abnormalities of lipid metabolism are associated with an increased risk of age related macular degeneration-the Western world's main cause of blindness. ${ }^{1}$ Statins (hydroxymethyl glutaryl coenzyme A reductase inhibitors) modify patients' lipid profile and lower their risk of coronary heart disease. $^{2}$ They also prevent stroke and, possibly, Alzheimer's disease. We report here an association between statin use and lower risk of age related macular degeneration.

\section{Participants, methods, and results}

We wrote to 660 men and women aged 66-75 who had been traced by the Office for National Statistics using information from their birth record at the Jessop Hospital for Women, Sheffield. Of these, 412 (62\%) agreed to take part and were interviewed at home. We recorded their use of drugs, including statins, currently and in the previous five years, and their history of cardiovascular disease. The participants were invited to 
MRC

Environmental

Epidemiology Unit,

(University of

Southampton),

Southampton

General Hospital,

Southampton

SO16 6YD

Nigel F Hall

Wellcome research

fellow

Catharine R Gale

research fellow

Holly Syddall

statistician

David I W Phillips

professor

Christopher N

Martyn

epidemiologist
Numbers (\%) of participants with age related macular

degeneration in either eye by use of statins

\begin{tabular}{lcc} 
& \multicolumn{2}{c}{ Age related macular degeneration* } \\
\cline { 2 - 3 } Statin use & Absent & Present \\
\hline No $(n=352)$ & $276(78.4)$ & $76(21.6)$ \\
\hline Yes $(n=27)$ & $26(96.3)$ & $1(3.7) \dagger$ \\
\hline All $(n=379)$ & $302(79.7)$ & $77(20.3)$
\end{tabular}

*Early or late age related macular degeneration in either eye as determined by the Wisconsin age related maculopathy grading system.

$\dagger P=0.02$ (Fisher's exact test) for macular degeneration versus none.

a clinic at the Northern General Hospital, Sheffield, and 392 (95\% of those interviewed) attended, where stereoscopic photos of both fundi were taken. Photographs were graded by one observer $(\mathrm{NFH})$, who was unaware of the participants' drug history, against standard images using the Wisconsin age related maculopathy grading system. ${ }^{3}$ We excluded 12 participants who had non-age related degenerative macular changes and one participant who was taking part in a trial of statins. The analyses that follow are therefore based on 379 participants.

Of the 379 subjects, $27(7 \%)$ reported taking statins and $77(20 \%)$ had some evidence of macular degeneration. Age related macular degeneration was more common among the participants who did not take statins (see table ): $76 / 352$ (22\%) of participants who did not take statins showed signs of macular degeneration, compared with only $1 / 27$ (4\%) of participants taking statins $(\mathrm{P}=0.02$, Fisher's exact test). This is equivalent to an odds ratio for macular degeneration among participants who took statins of $0.14(95 \%$ confidence interval 0.02 to 0.83) compared with those who did not.

A history of coronary artery bypass grafting or angioplasty was associated with macular degeneration. Eight of the 77 participants with macular degeneration $(10 \%)$ had undergone coronary angioplasty or bypass grafting compared with 13 of the 302 participants (4\%) without macular degeneration $(\mathrm{P}=0.05$, Fisher's exact test). Not surprisingly, people who had undergone coronary angioplasty or bypass grafting were more likely to have taken statins than those who had not $(6 / 22$ (27\%) compared with $21 / 389(5 \%)$ respectively). In a logistic regression model-after adjustment for age, sex, smoking, and history of coronary angioplasty or bypass grafting-the odds ratio for macular degeneration (early or late) among participants taking statins was 0.09 (0.01 to 0.73 ) compared with those who did not take the drug.

\section{Comment}

In this survey of men and women aged 66-75 those who took statins had an eleventh the risk of age related macular degeneration (after adjustment for coronary artery disease and smoking) compared with those not taking the drug. The confidence intervals are wide, however, giving an imprecise estimate of the reduced risk. Bias could lead to this association if people with macular degeneration and taking statins were less likely to participate, or people without macular degeneration and not taking statins were more likely to participate, but this seems unlikely.

We suggest three mechanisms that could link statin use with lower risk of macular degeneration. Firstly, statins might prevent the accumulation of basal linear deposit in Bruch's membrane, which occurs with higher concentrations of plasma cholesterol. ${ }^{4}$ Secondly, antioxidant properties of statins might protect the outer retina from oxidative damage. Thirdly, simvastatin inhibits endothelial cell apoptosis and preserves ischaemic vasculature, ${ }^{5}$ perhaps maintaining a competent vascular supply to the macula.

We thank Sheila Walton and Elizabeth Kelleher, research nurses, for their help with the fieldwork.

Contributors: NFH, CRG, DIWP, and CNM formulated the design of the study. NFH and CRG carried out the fieldwork. HS analysed the data. The paper was written by NFH and CNM, and edited by CNM, CRG, and DIWP. NFH and CNM are guarantors for the paper.

Funding: This study was funded by the Wellcome Trust and the Medical Research Council.

Competing interests: None declared.

Bressler NM. Age related macular degeneration. BMJ 2000;321:1425-7.

2 Pignone M, Phillips C, Mulrow C. Use of lipid lowering drugs for primary prevention of coronary heart disease: meta-analysis of randomised trials. BMJ 2000;321:983-6

3 Klein R, Davis MD, Magli YL, Segal P, Klein BEK, Hubbard L. The Wisconsin age-related maculopathy grading system. Ophthalmology 1991;98:1128-31.

4 Dithmar S, Curcio CA, Le N-A, Brown S, Grossniklaus HE. Ultrastructural changes in Bruch's membrane of apolipoprotein E-deficient mice. Invest Ophthalmol Vis Sci 2000;41:2035-42.

5 Kureishi Y, Luo Z, Shiojima I, Bialik A, Fulton D, Lefer DJ, et al. The HMG-CoA reductase inhibitor simvastatin activates the protein kinase Akt and promotes angiogenesis in normocholesterolemic animals. Nature Med 2000;6:1004-10.

(Accepted 25 June 2001)

\title{
Antenatal detection of HIV: national surveillance and unlinked anonymous survey
}

\author{
Susan Cliffe, Pat A Tookey, Angus Nicoll
}

continued over

BMJ 2001;323:376-7

\section{bmj.com}

Details of methods are on the BMJ's website
In 1999 national targets were adopted for the universal offer and recommendation of a test for HIV during antenatal care throughout England. ${ }^{1}$ This built on earlier initiatives aimed at enhancing maternal diagnosis of HIV infection and reducing perinatal transmission of HIV with appropriate interventions. ${ }^{2}$ Substantial improvement in the proportion of maternal HIV infections diagnosed has been reported for much of London, and improvement has been observed more recently for the rest of England. ${ }^{3}$ We used published estimates of rates of vertical transmission of HIV in the United Kingdom to assess whether the target of an $80 \%$ reduction in the proportion of vertically infected infants by December 2002 is likely to be achieved. ${ }^{1}$

\section{Participants, methods, and results}

We used results from the unlinked anonymous dried blood spot survey to estimate the number of births in 